Int. J. Electrochem. Sci., 13 (2018) $4251-4266$

\title{
Electrochemical Behavior of Butylated Hydroxyanisole and Butylated Hydroxytoluene in Acetic Acid Solutions and their Voltammetric Determination in Pharmaceutical Preparations
}

\author{
Magdalena Jakubczyk, Slawomir Michalkiewicz* \\ Institute of Chemistry, Jan Kochanowski University, Swietokrzyska St. 15G, PL-25406 Kielce, Poland \\ *E-mail: smich@ujk.edu.pl
}

doi: $10.20964 / 2018.05 .76$

Received: 8 January 2018 / Accepted: 3 March 2018 / Published: 10 April 2018

\begin{abstract}
Electrochemical behavior of butylated hydroxyanisole (BHA) and butylated hydroxytoluene (BHT) was investigated by cyclic (CV), linear sweep (LSV) and differential pulse voltammetry (DPV) in glacial acetic acid solutions in order to develop a new method for determination of these synthetic antioxidants. A glassy carbon electrode (GC) and a carbon fiber disk microelectrode (CF) were used as working electrodes. Voltammograms recorded at these electrodes show well-defined single waves or peaks attributed to the oxidation of BHA and BHT which proceeds with an irreversible exchange of two electrons. A separation of about $0.24 \mathrm{~V}$ between the peak potentials recorded using DPV in their binary mixtures was obtained. Wide linearity ranges were achieved: $0.03-594.62,0.18-921.37 \mathrm{mg} \mathrm{L}^{-1}$ and low limits of detection were $0.01,0.06 \mathrm{mg} \mathrm{L}^{-1}$ for butylated hydroxyanisole and butylated hydroxytoluene, respectively. The results obtained indicate that DPV at CF microelectrode allows sensitive, precise, accurate, and fast determination of BHA and BHT, alone or in their mixture in pharmaceuticals without the need for their separation from the matrices, and can be an analytical alternative for existing methods.
\end{abstract}

Keywords: Butylated hydroxyanisole (BHA), Butylated hydroxytoluene (BHT), Acetic acid, Microelectrodes, Voltammetry, Determination

\section{$\underline{\text { FULL TEXT }}$}

(C) 2018 The Authors. Published by ESG (www.electrochemsci.org). This article is an open access article distributed under the terms and conditions of the Creative Commons Attribution license (http://creativecommons.org/licenses/by/4.0/). 